\title{
Histopathological Features of Listerial Rhombencephalitis in Dairy Calves in Kazakhstan
}

\author{
Assem Serikovna Ibazhanova ${ }^{{ }^{*}}$, Zhuldyzaj Zhakabaevna Kenzhebekova ${ }^{1}$, Banu Omirtajkyzy Nurgazy ${ }^{1}$, Damir \\ Mikdatovich Khussainov ${ }^{1}$, Ajdar Myrzahmetuly Namet ${ }^{4}$, Ajtbaj Ajtkenovich Alimov ${ }^{2}$ and Kanat Amanzholovich \\ Orynkhanov ${ }^{3}$ \\ ${ }^{I}$ Department of Biological Safety, Kazakh National Agrarian University, 050000 Almaty, Kazakhstan \\ ${ }^{2}$ Department of Veterinary Sanitation Expertise and Hygiene, Kazakh National Agrarian University, 050000 Almaty, Kazakhstan \\ ${ }^{3}$ Department of Obstetrics, Surgery and Biotechnology of Reproduction of Animals, Kazakh National Agrarian University, 050000 Almaty, Kazakhstan \\ ${ }^{4}$ Kazakh Research Veterinary Institute, 050016 Almaty, Kazakhstan \\ *Corresponding author's Email: assemibazhanova@yahoo.com; (iD ORCID: 0000-0002-2833-1413
}

\begin{abstract}
Listeriosis is an infectious disease with zoonotic potential and can cause high fatality rates in animals and humans. Although the available evidence demonstrates the significance of post-mortem histological evaluation in the appropriate diagnosis, there is no sufficient evidence addressing histopathological alterations observed in calves clinically suspected of listeriosis. The current study aimed to carry out a post-mortem analysis of the dairy calves with clinical suspicion of listeriosis and determine a condition that contributed to death using histopathological evaluation. The tissue samples were obtained from 16 dairy calves with the age range of one day to one month, which died presumably due to listeriosis on several livestock farms in the Almaty region of Kazakhstan. The calves had symptoms of neurologic dysfunction prior to death. Necropsy and collection of brain histological specimens were performed, followed by procedures of fixation, dehydration, paraffinization, sectioning, staining with hematoxylin, and eosin along with Levaditi's method, and the microscopic examination. The histopathology findings were consistent with infection by Listeria monocytogenes and localized to the brainstem leading to the diagnosis of listerial rhombencephalitis.
\end{abstract}

Keywords: Brain, Calves, Histopathology, Listeria monocytogenes, Listeriosis, Rhombencephalitis

\section{INTRODUCTION}

A facultative anaerobic bacterium Listeria monocytogenes is the causative organism of listeriosis (Todd and Notermans, 2011) and is disseminated through the oral route predominantly (Gelbíčová et al., 2016). Ruminants and monogastric animals may cause listeria infection in humans, constituting a particular hazard to individuals with various immune system vulnerabilities, including infants, organ transplantation patients, and others. The mortality rate for listeriosis is up to $75 \%$ in humans and up to $100 \%$ in animals. Animals under three years of age are more susceptible to the disease (Chlebicz and Śliżewska, 2018). Moreover, this intracellular pathogen is capable of permeating the placental barrier (David and Cossart, 2017), which poses substantial risks to human and animal fetuses. For instance, the transmission during pregnancy may lead to congenital infection (St Edmunds et al., 2008). As a reflection of this data, a survey of 1500 dairy farmers conducted by Erdogan et al. (2001) showed the highest within-herd incidence of clinical listeriosis in dairy calves and replacement heifers. According to a study performed on 20 dairy farms in the northern hemisphere, the average yearly prevalence of $L$. monocytogenes was more than twice as high among calves compared to cows (Bandelj et al., 2018). Concerning the nervous form of listeriosis affecting the central nervous system (CNS), such as rhombencephalitis, a retrospective cohort study revealed that the mean age of sheep and cattle with neurolisteriosis was 39 months (Giles et al., 2017).

The methods usually carried out to confirm the diagnosis of bovine listeriosis are histopathology and culture tests (Radostits et al., 2007). The advantages of histopathology include low cost and ability to observe the tissue reaction (Gupta et al., 2009). Inherent operator variability is among its limitations (Fernandez et al., 2005). Listeria monocytogenes can be detected by silver impregnation staining techniques (Topalovski et al., 1993; Luca et al., 2015; Wilson et al., 2015). Their advantage is high sensitivity (Rabilloud, 2012), whereas the imperfection is poor suitability for quantification (Weiss et al., 2009). As for the present study, brain tissues were stained by Levaditi's silver impregnation method. Molecular tests frequently used for the identification of pathogenic material are immunohistochemistry and polymerase chain reaction (PCR). Due to the quantitativeness of the latter, it is less sensitive to interobserver variability (Furrer et al., 2015). Immunohistochemistry allows the identification of specific antigens within tissue sections (Duraiyan et al., 2012). One of its drawbacks is the complexity of the interpretation of results owing to different specificity and sensitivity of commercial antibodies (Furrer et al., 2015). Besides, as Kim et al. (2016) 
has remarked, more sensitive methods spawn increased background signal aside from the target signal. Interestingly, Peters et al. (1995) stated that the clinical diagnosis of listeric encephalitis was confirmed in eight of eleven cerebrospinal fluid samples from ruminants by histological and/or bacteriological examination, whereas PCR allowed detecting L. monocytogenes in only one of the samples.

The authors point out a considerable role of postmortem inspections, including histological examination, in a correct diagnosis for listeriosis. At the same time, it must be recognized that no ample evidence addressing histopathological alterations observed in calves with clinical suspicion of listeriosis is available. Therefore, the aim of this cross-sectional study was to carry out a post-mortem analysis of the dairy calves' tissues and determine a condition that contributed to their death using histopathological evaluation.

\section{MATERIALS AND METHODS}

This study was carried out at the Department of Biological Safety at Kazakh National Agrarian University, Kazakhstan between 2018 and 2019. The test materials were tissue samples obtained from 16 dairy calves ranging in age from one day to one month, which died presumably due to listeriosis, displaying symptoms of neurologic dysfunction prior to death on several livestock farms in Almaty region of Kazakhstan. The provisional diagnosis was made by rural veterinarians with higher education in the veterinary field. Clinical manifestations included throwing head back, muscle tremors, circling, gait abnormalities, and recumbency. On the day of the calves' death, in order to establish its cause, they were delivered to the department by farm workers. The above cranial neuropathies allowed narrowing the diagnosis to rhombencephalitis (Bradshaw and Venkatesan, 2016). Necropsy and collection of brain histological specimens were performed. The pathological specimens were routinely fixed in $10 \%$ neutral buffered formalin and Carnoy's solution. Paraffin and cryostat 5-10 $\mu \mathrm{m}$ sections were stained with hematoxylin-eosin. Levaditi's technique was used to detect $L$. monocytogenes in the samples (Drury et al., 1967). The slices were examined under Zeiss Axiostar plus microscope (Zeiss Inc., Göttingen, Germany) and micrographs were captured by means of a microscope-mounted Leica digital camera (Leica Camera AG, Wetzlar, Germany), at magnifications of 150x and 300x.

\section{Ethical approval}

All procedures involving the animals were carried out in conformity with Directive 2010/63/EU and were approved by the ethics committee of Kazakh National Agrarian University (Kazakhstan).

\section{RESULTS}

According to the results of the histopathological assessment, in the medulla oblongata and pons Varolii, accumulations of lymphocytes, histiocytes, and neutrophils were observed. The blood vessels were hyperemic and thickened 5 to 319 times $(16.5-1052.8 \mu \mathrm{m})$. Thus, in the region of the medulla oblongata adjacent to the fourth cerebral ventricle, we noted necrotic foci, lymphoneutrophilic pleocytosis, neuronal damage (chromatolysis, acute swelling, vacuolization, pycnosis, translucent cell formation), diapedesis, inflammatory cell infiltrates around blood vessels, perivascular and pericellular edema. The damaged neurons were surrounded by glial cells (Figure 1).

Lymphoneutrophilic pleocytosis, edema, and necrotic foci of approximately $105 \mu \mathrm{m}$ (the largest foci were up to $1300 \mu \mathrm{m})$ were found underneath the ependyma of the fourth ventricle as well. In the necrotic foci, Listeria were Levaditi-stained black (Figure 2). The disease was confirmed by Levaditi's staining in all sixteen calves.

In the cerebellum, many Purkinje cells were edematous, their nuclei shriveled or poorly stained, the vessels were congested, and hemorrhages were found, along with cellular infiltrates comprised of lymphocytes, neutrophils, and histiocytes. These histopathologic changes are concordant with infection by L. monocytogenes and localized to the brainstem, which therefore led to the diagnosis of listerial rhombencephalitis.

\section{DISCUSSION}

The predilection of L. monocytogenes for brainstem is widely acknowledged (Xu et al., 2019). In the current study, histopathological examination of specimens from dairy calves with neurological manifestations revealed cerebral tissue inflammation enveloping hindbrain structures, which is characteristic of rhombencephalitis (Oevermann et al., 2010). Cell populations involved in the intracerebral immune response against $L$. monocytogenes-induced lesions overlap those reported in animals (Haligur et al., 2019). In addition to the already asserted axonal pathway of L. monocytogenes into the CNS, the transneuronal spread was hypothesized for this infectious agent (Henke et al., 2015). The observed neuronal necrosis phenomenon is a common sequel of encephalitis, although is not yet explained explicitly. It is alleged to be caused by metabolites of infiltrating neutrophils or neuronal infection engendered by L. monocytogenes (Precht et al., 2018). 


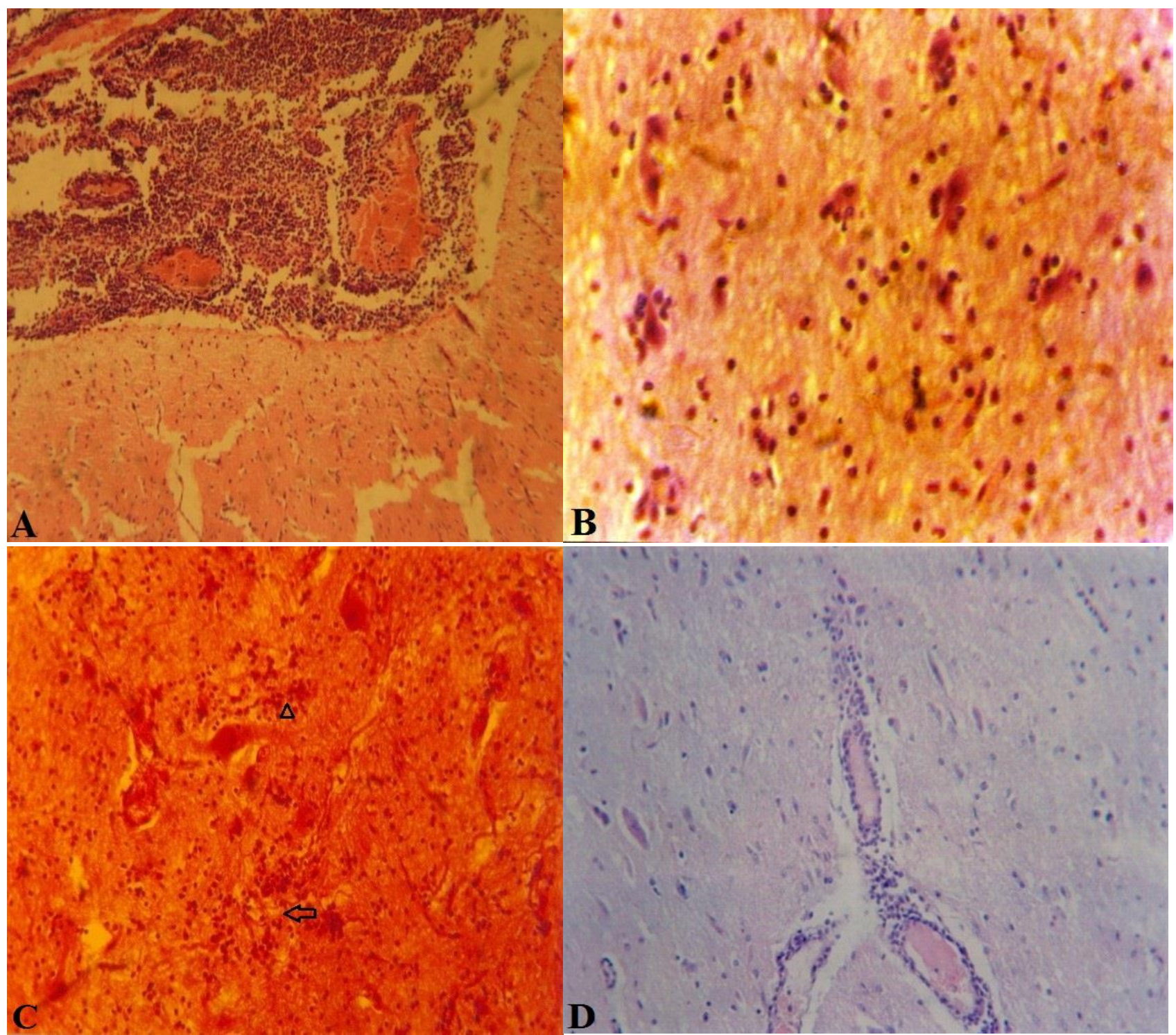

Figure 1. Histological features of listerial rhombencephalitis in the medulla oblongata of calves' brain that died with neurological signs. A: multifocal and coalescing foci of necrosis and hemorrhage, with lymphocytes, neutrophils and histiocytes. Hematoxylin and Eosin (H\&E) stain, 150x; B: neuronophagia. H\&E, 300x; C: neuronal dystrophy (arrow) and glial cell proliferation (arrowhead). H\&E, 150×; D: inflammatory perivascular cuffs. H\&E, 150×

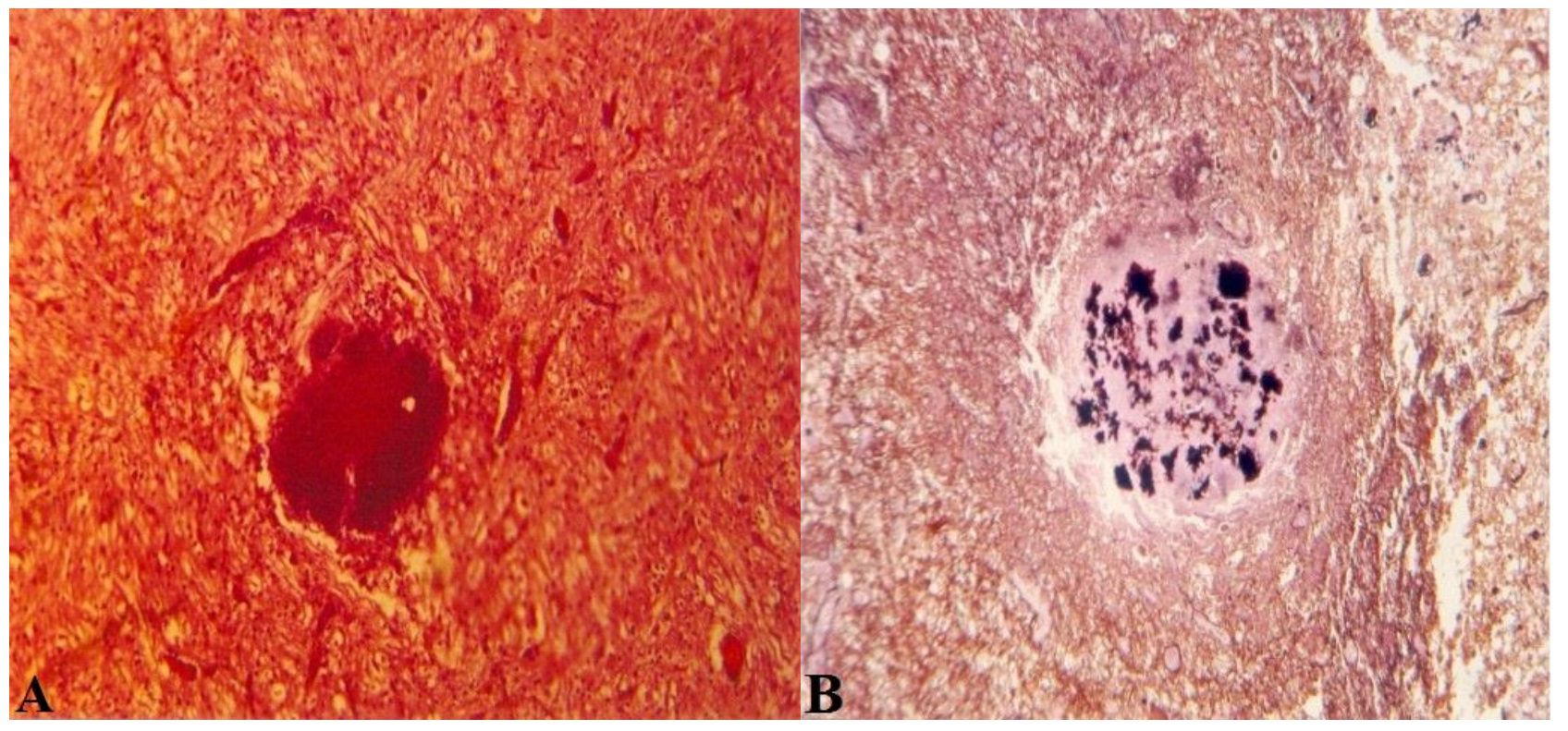

Figure 2. Histological features of listerial rhombencephalitis in the fourth cerebral ventricle of calves that died with neurological signs: A: necrotic focus. H\&E, 150x; B: Listeria monocytogenes (black) in necrotic focus. Levaditi stain, $150 \times$ 
Another complication associated with L. monocytogenes infection is ventriculitis. In our case, the fourth ventricle was found edematous. However, we have not managed to retrieve any research publication containing information on similar alterations in the fourth ventricle of animals with listeriosis. Inter alia, dilatation of the fourth ventricle, as well as inflammation of its choroid plexus and ependyma have been previously described by other authors in human listeriosis of various forms (Engelen-Lee et al., 2018; Liang et al., 2019).

Perivascular infiltration of inflammatory cells was detected in the medulla sections from the calves' brain, since neuroinvasive L. monocytogenes infection triggers the inflammatory cascade. In particular, it recruits miRNA-155 which increases inflammation of the cerebral tissue via a variety of inflammatory cells, such as interferon $\gamma$-secreting lymphocytes, invading the brain and activating microglia during the adaptive immune response (Zhang et al., 2018).

The evidence confirms the extension of the brainstem encephalitis to the cerebellum (Coombs, 2017), which is in compliance with the data obtained in the current research. Nonetheless, this phenomenon is rarely reported in cattle, but, as revealed by Guldimann et al. (2015), L. monocytogenes can propagate in all microglia, including even those of the hippocampus. An experiment on ruminant rhombencephalitis (Rocha et al., 2013) indicated the presence of microabscesses and mononuclear perivascular cuffing in the white matter of bovine cerebellum.

The limitation of the current study is in the lack of an immunoassay or PCR analysis. Despite the prevalence of these diagnostic techniques, they also have a number of disadvantages, such as cross-reactivity (Favrot, 2015; Sakamoto et al., 2018; Ahmed et al., 2020). Furthermore, histopathological assessment is pathognomonic and is still exploited in some researches for confirmation of listeriosis (Teixeira et al., 2011; Precht et al., 2014).

\title{
CONCLUSION
}

This research provided an opportunity to investigate histopathological manifestations of listerial rhombencephalitis in dairy calves. The results indicate that L. monocytogenes produced destructive changes in parenchymal cells and brain microvascular system of the investigated animals. Based on the characteristic clinical signs and the obtained findings during histopathological examination, severe multifocal rhombencephalitis associated with L. monocytogenes infection was diagnosed.

\section{DECLARATIONS}

\author{
Acknowledgments \\ English. \\ Authors are grateful to Sergey Sergeevich Kozhevnikov for the translation of this manuscript from Russian into
}

\section{Authors' contribution}

A. Ibazhanova and Zh. Kenzhebekova performed the histopathological examination (including necropsy and sample collection) and manuscript writing. B. Nurgazy supervised the laboratory procedures and participated in interpretation of results. A. Namet and K. Orynkhanov provided a critical review. D. Khussainov and A. Alimov prompted a number of literature sources for introduction and discussion sections.

\section{Competing interests}

The authors have not declared any conflict of interest.

\section{REFERENCES}

Ahmed S, Ning J, Peng D, Chen T, Ahmad I, Ali A, Lei Z, Shabbir MA, Cheng G and Yuan Z (2020). Current advances in immunoassays for the detection of antibiotics residues: a review. Food and Agricultural Immunology, 31(1): 268-290. DOI: https://doi.org/10.1080/09540105.2019.1707171

Bandelj P, Jamnikar-Ciglenecki U, Ocepek M, Blagus R and Vengust M (2018). Risk factors associated with fecal shedding of Listeria monocytogenes by dairy cows and calves. Journal of Veterinary Internal Medicine, 32(5): 1773-1779. DOI: https://doi.org/10.1111/jvim.15234

Bradshaw MJ and Venkatesan A (2016). Herpes simplex virus-1 encephalitis in adults: pathophysiology, diagnosis, and management. Neurotherapeutics, 13(3): 493-508. DOI: https://doi.org/10.1007/s13311-016-0433-7

Chlebicz A and Śliżewska K (2018). Campylobacteriosis, salmonellosis, yersiniosis, and listeriosis as zoonotic foodborne diseases: a review. International Journal of Environmental Research and Public Health, 15(5): 1-29. DOI: https://doi.org/10.3390/ijerph15050863

Coombs KM (2017). Infections of the Cerebellum. In: H. Marzban (Editor), Development of the Cerebellum from Molecular Aspects to Diseases. Contemporary Clinical Neuroscience, Springer, Cham, Switzerland, p. 248. DOI: https://doi.org/10.1007/978-3-31959749-2_12

David DJ and Cossart P (2017). Recent advances in understanding Listeria monocytogenes infection: the importance of subcellular 
and physiological context. F1000Research, 6(F1000 Faculty Rev): p. 1126. DOI: https://doi.org/10.12688/f1000research.11363.1

Drury RAB, Wallington EA and Cameron SR (1967). Carleton's histological technique. Oxford University Press, New York, p. 520.

Duraiyan J, Govindarajan R, Kaliyappan K and Palanisamy M (2012). Applications of immunohistochemistry. Journal of Pharmacy \& Bioallied Sciences, 4(Suppl 2): S307. DOI: https://doi.org/10.4103/0975-7406.100281

Engelen-Lee JY, Koopmans MM, Brouwer MC, Aronica E and van de Beek D (2018). Histopathology of listeria meningitis. Journal of Neuropathology \& Experimental Neurology, 77(10): 950-957. DOI: https://doi.org/10.1093/jnen/nly077

Erdogan HM, Cripps PJ, Morgan KL, Cetinkaya B and Green LE (2001). Prevalence, incidence, signs and treatment of clinical listeriosis in dairy cattle in England. Veterinary Record, 149(10): 289-293. DOI: http://dx.doi.org/10.1136/vr.149.10.289

Favrot C (2015). Polymerase chain reaction: advantages and drawbacks. Proc "Congresso Latinoamericano de Dermatologia Veterinaria", Buenos Aires, Argentina, 26-27 November 2015: 3-6. Available at:

https://www.zora.uzh.ch/id/eprint/116536/1/Favrot_2015_Buenos_Aires_Polymerase.pdf

Fernandez DC, Bhargava R, Hewitt SM and Levin IW (2005). Infrared spectroscopic imaging for histopathologic recognition. Nature Biotechnology, 23(4): 469-474. DOI: https://doi.org/10.1038/nbt1080

Furrer D, Sanschagrin F, Jacob S and Diorio C (2015). Advantages and disadvantages of technologies for HER2 testing in breast cancer specimens. American Journal of Clinical Pathology, 144(5): 686-703. DOI: https://doi.org/10.1309/AJCPT41TCBUEVDQC

Gelbíčová T, Pantůček R and Karpíšková R (2016). Virulence factors and resistance to antimicrobials in Listeria monocytogenes serotype 1/2c isolated from food. Journal of Applied Microbiology, 121(2): 569-576. DOI: https://doi.org/10.1111/jam.13191

Giles L, Orr J, Viora L, Gutierrez-Quintana R, Logue D and Guevar J (2017). Ruminant neurological disease: a retrospective cohort study. Veterinary Record, 181(14): 372-373. DOI: http://dx.doi.org/10.1136/vr.104326

Guldimann C, Bärtschi M, Frey J, Zurbriggen A, Seuberlich T and Oevermann A (2015). Increased spread and replication efficiency of Listeria monocytogenes in organotypic brain-slices is related to multilocus variable number of tandem repeat analysis (MLVA) complex. BMC Microbiology, 15: 1-9. DOI: https://doi.org/10.1186/s12866-015-0454-0

Gupta E, Bhalla P, Khurana N and Singh T (2009). Histopathology for the diagnosis of infectious diseases. Indian Journal of Medical Microbiology, 27(2): 100-106. DOI: https://doi.org/10.4103/0255-0857.49423

Haligur M, Aydogan A, Ozmen O and Ipek V (2019). Immunohistochemical evaluation of natural cases of encephalitic listeriosis in sheep. Biotechnic \& Histochemistry, 94(5): 341-347. DOI: https://doi.org/10.1080/10520295.2019.1571225

Henke D, Rupp S, Gaschen V, Stoffel MH, Frey J, Vandevelde M and Oevermann A (2015). Listeria monocytogenes spreads within the brain by actin-based intra-axonal migration. Infection and Immunity, 83(6): 2409-2419. DOI: https://doi.org/10.1128/iai.00316-15

Kim SW, Roh J and Park CS (2016). Immunohistochemistry for pathologists: protocols, pitfalls, and tips. Journal of Pathology and Translational Medicine, 50(6): 411-418. DOI: https://doi.org/10.4132/jptm.2016.08.08

Liang JJ, He XY and Ye H (2019). Rhombencephalitis caused by Listeria monocytogenes with hydrocephalus and intracranial hemorrhage: A case report and review of the literature. World Journal of Clinical Cases, 7(4): 538-547. DOI: https://dx.doi.org/10.12998/wjcc.v7.i4.538

Luca CD, Donati L, D’Oria L, Licameli A, Pellegrino M and Santis MD (2015). Listeria infection in pregnancy: a review of literature. The Open Infectious Diseases Journal, 9(1): 2-25. DOI: https://doi.org/10.2174/1874279301509010020

Oevermann A, Zurbriggen A and Vandevelde M (2010). Rhombencephalitis caused by Listeria monocytogenes in humans and ruminants: A Zoonosis on the rise?. Interdisciplinary Perspectives on Infectious Diseases, 632513: 1-22. DOI: https://doi.org/10.1155/2010/632513

Peters M, Pohlenz J, Jaton K, Ninet B and Bille J (1995). Studies of the detection of Listeria monocytogenes by culture and PCR in cerebrospinal fluid samples from ruminants with listeric encephalitis. Journal of Veterinary Medicine, series B, 42(1-10): 84-88. DOI: https://doi.org/10.1111/j.1439-0450.1995.tb00686.x

Precht C, Diserens G, Vermathen M, Oevermann A, Lauper J and Vermathen P (2018). Metabolic profiling of listeria rhombencephalitis in small ruminants by $1 \mathrm{H}$ high-resolution magic angle spinning NMR spectroscopy. NMR in Biomedicine, 31(12): 1-20. DOI: https://doi.org/10.1002/nbm.4023

Precht MC, Oevermann A, Lauper J and Gorgas D (2014). Listeria brainstem encephalitis in small ruminants: correlation of magnetic resonance imaging and histopathology. Veterinary Radiology \& Ultrasound, 55(6): 651-679. DOI: https://doi.org/10.7892/boris.96424

Rabilloud T (2012). Silver staining of 2D electrophoresis gels. In: K. Marcus, M. Eisenacher and B. Sitek (Editors), Quantitative Methods in Proteomics, Humana Press, Totowa, pp. 61-73 (USA). DOI: https://doi.org/10.1007/978-1-61779-885-6_5

Radostits OM, Gay CC, Hinchcliff KW and Constable PD (2006). Veterinary Medicine E-Book: A textbook of the diseases of cattle, horses, sheep, pigs and goats. Elsevier Health Sciences, New York, p. 805.

Rocha PRDA, Lomonaco S, Bottero MT, Dalmasso A, Dondo A, Grattarola C, Zuccon F, Iulini B, Knabel SJ, Capucchio MT and Casalone C (2013). Ruminant rhombencephalitis-associated Listeria monocytogenes strains constitute a genetically homogeneous group related to human outbreak strains. Applied and Environmental Microbiology, 79(22): 3059-3066. DOI: https://doi.org/10.1128/AEM.02923-13

Sakamoto S, Putalun W, Vimolmangkang S, Phoolcharoen W, Shoyama Y, Tanaka H and Morimoto S (2018). Enzyme-linked immunosorbent assay for the quantitative/qualitative analysis of plant secondary metabolites. Journal of Natural Medicines, 72(1): 32-42. DOI: https://doi.org/10.1007/s11418-017-1144-z

St Edmunds B, Langford L, Leahurst L, Newcastle P, Preston R, Starcross S and Bonington T (2008). Multifocal necrotising hepatitis in a neonatal calf caused by Listeria monocytogenes. Veterinary Record, 162(23): 739-742. DOI: http://dx.doi.org/10.1136/vr.162.23.739 
Teixeira AB, Lana AMA, Lamounier JA, da Silva OP and Eloi-Santos SM (2011). Neonatal listeriosis: the importance of placenta histological examination — a case report. AJP Reports, 1(1): 3-6. DOI: http://dx.doi.org/10.1055/s-0030-1271216

Todd ECD and Notermans S (2011). Surveillance of listeriosis and its causative pathogen, Listeria monocytogenes. Food Control, 22(9): 1484-1490. DOI: https://doi.org/10.1016/j.foodcont.2010.07.021

Topalovski M, Yang SS and Boonpasat Y (1993). Listeriosis of the placenta: clinicopathologic study of seven cases. American Journal of Obstetrics and Gynecology, 169(3): 616-620. DOI: https://doi.org/10.1016/0002-9378(93)90632-S

Weiss W, Weiland F and Görg A (2009). Protein detection and quantitation technologies for gel-based proteome analysis. In: J. Reinders and A. Sickmann (Editors), Proteomics, Humana Press, Totowa, pp. 59-82 (USA). DOI: https://doi.org/10.1007/978-160761-157-8_4

Wilson CB, Nizet V, Maldonado Y, Remington JS and Klein JO (2015). Remington and Klein's infectious diseases of the fetus and newborn infant. Elsevier Health Sciences, New York, p. 462.

Xu R, Bai Y, Duan C, Zhao S, Chen X and Yang Q (2019). Central nervous system Listeria monocytogenes infection mimicking central nervous system idiopathic inflammatory demyelinating disease. Infection and Drug Resistance, 12: 255-259. DOI: https://doi.org/10.2147/IDR.S189930

Zhang M, Gillaspy A, Gipson JR, Cassidy BR, Nave JL, Brewer MF, Stoner JA, Chen J and Drevets DA (2018). Neuroinvasive Listeria monocytogenes infection triggers IFN-activation of microglia and upregulates microglial miR-155. Frontiers in Immunology, 9: 1-22. DOI: https://doi.org/10.3389/fimmu.2018.02751 